\title{
O PROBLEMA ETIOLÓGICO DA HIDRONEFRÓSE
}

\author{
DR. ABDUHADER ADURA \\ (Assistente voluntário da Cadeira).
}

\section{1 - GENERALIDADES}

O termo hidronefrose foi empregado pela primeira vez por RAYER, èm 1841, no seu livro "Traité des Maladies des Reins".

Sinonímia: Hidrops renales (Rokitansky), Hidrops renis (Martineau), Utronefrose (Guyon e Albarran), Rim Saxiforme (Küster), Nefrohidrose (Aschoff), Nefrectasia (Morris), Constipação Renal (Lichtenberg).

\section{2- DEFINIÇÃO}

Marion em seu "Traité d'Urologie" escreve que a hidronefrose é constituida pela dilatação aséptica do bacinete e às vezes do rim.

Entretanto, há quem afirme não ser sempre aséptica a urina na hidronefrose, reservando-se a denominação hidropionefrose às retenções complicadas de infecção.

$O$ termo hidronefrose, escreve Forgue, foi creado por RAYER querendo significar que a urina, retida na bolsa renal, sofre verdadeira hidratação e toma caráter aquoso, por diminuição da densidade dos sais e das materias extrativas.

Referindo-se à hidronefrose diz Lichtenberg: "Este nọme se dá a tudo que se apresenta como dilatação da pelvis renal, sem se levar em consideração o fator provocador destas alterações e sem que se tenha, tão pouco, a extensão topográfica desta dilatação sôbre as vias de excreção. Este termo engloba o conceito de um aumento da pelvis renal; nada caracteriza melhor a insuficiencia clínica desta designação que o fato de se falar em hidronefroses anãs e de prehidronefroses".

Continua o urologista alemão afirmando: "Mediante esta inversão de lógica todos se julgam livres da obrigação de aclarar a

$\left(^{*}\right)$ As fotografias que ilustram esta compilaçāo são todas de casos clinicos do Dr. Darcy Vilela Itiberé. Ao conhecido e distinto urologista, os nossos agradecimentos. 
essëncia da enfermidade. A grande variedade de urogramas de enchimento ou acendentes já há muitos anos me determinou fazer resaltar:

$\left.1 .^{\circ}\right)$ que aquilo que em geral se designa como hidronefrose não é uma enfermidade única.

2..$^{\circ}$ ) que na patologia das vias urinárias, resultados morfologicamente semelhantes podem produzir-se por causas diversas.

3. $\left.{ }^{\circ}\right)$ que somente considerando a patogenia é que se pode conceber um tramento etiologico conservador destas enfermidades".

Baseado nestes arg:mentos, Lichtenberg propõe se afaste a denominação hidronefrose, criando o de constipação das vias urinárias, afirmando que a base de interpretação da mesma é dada pela. fisiologia e fisiopatologia da musculatura lisa das vias excretoras do aparelho urinário. Escreve mesmo, o Autor citado linhas acima, que êste "problema muscular" deve ocupar lugar destacado nas nossas cogitações quando nos propômos a realizar a terapêutica da hidronefrose.

\section{ETIOLOGIA}

As condições que causam obstrução ou estase podem ser reunidas, segundo Hinman, conforme demonstra o esquema da pagina seguinte.

Analisando sumariamente a classificação de Hinman poderemos. dizer que as causas mecânicas congênitas são representadas por máformação do aparelho urinário; ora localizadas no tracto inferior, ora no tracto superior.

Quanto às causas mecânicas adquiridas, estas podem comprometer o livre escoamento da urina por diversos modos. Ei-los:

a) o agente é externo à via excretora e atúa sôbre a parede dos órgãos motivando diminuição, até mesmo obstrução do lumen. (figura n.0 1).

b) o agente atúa em plena luz do órgão (figura n.$^{\circ} 2$ ).

c) o agente está situado no seio da parede do órgão (figura n. ${ }^{\circ}$ 3) e, crescendo em direção a sua luz, pode vir determinar perturbação à livre passagem da urina (figura n. ${ }^{\circ} 4$ ).

d) Mudança de posição do rim ou de posição e direção do ureter, com consequente origem de curvaturas ou angulações ' nêste ultimo órgão (fig. n. ${ }^{\circ} 5$ ).

As causas neurogênicas assumem grande importância na etiología da hidronefrose, por alterarem a dinâmica pielo-ureteral.

Antes de nos preocuparmos com o fatôr essencial para a instalação da hidronefrose, vamos nos deter sôbre a dinâmica pielo-ureteral, cuja perturbação acarreta graves prejuizos na excreção urinaria. 


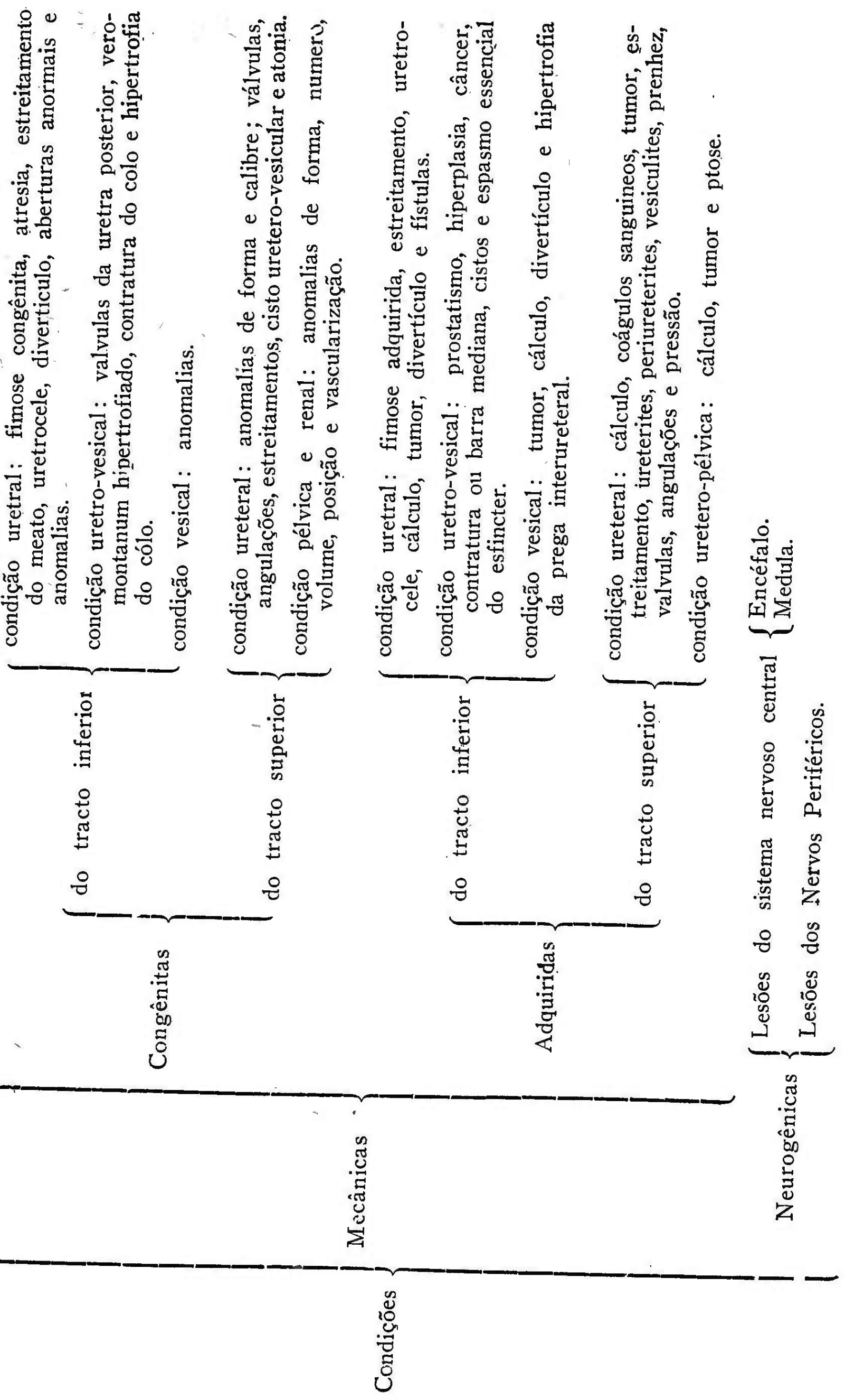


99

(1)

(9) 


\section{DINÂMICA PIELO-URETERAL (*)}

Ficou demonstrado que calices, bacinete e ureter não possuem papel simplesmente passivo na eliminação de urina, pois são capazes
de se contrairem.

Possuem êsses órgãos movimentos peristálticos, e os apresentam mesmo que em seus lumens não exista urina.

Estudando o ureter, Engelman verificou a presença de sistole, diastole e uma pausa. As contrações peristálticas que percorrem ritmicamente o ureter, com uma velocidade de 2 a $3 \mathrm{cms}$. por segundo sucedem-se em intervalos de um quarto de minuto a um minuto, conforme a intensidade do funcionamento renal.

Experimentalmente excitando um determinado ponto do ureter produzem-se duas ondas: uma inferior à zona excitada que é isoperistáltica, outra superior que é antiperistáltica (aparece somente nos (asos patológicos).

()bservam-se no ureter isolado do corpo diminutas contrações que se propagam nos dois sentidos. Para Gaskell êstes movimentos dependem do funcionamento de um dispositivo nervoso autonomo. Starling acha que são puramente miogênicos. O automatismo desses segmentos das vias excretoras do aparelho urinário é garantido pelos elementos nervosos contidos na parede dos mesmos. Tal fato explica a permanência do peristaltismo desses órgãos, quando retirados do corpo, como bem evidenciam numerosas experiências.

A genese das ondas peristálticas parte de elementos nervosos (células ganglionares) contidos na parede dos órgãos em estudo.

Para Hryntschok não existem células ganglionares na parede do bacinete. Segundo Stoehr o ureter encerra um numero variavel, que cresce a medida que se aproxima da bexiga.

$\mathrm{O}$ automatismo da musculatura lisa dos calices, bacinete $\mathrm{e}$ ureter tem grande valor, pois como ensina Lichtenberg, ele só, basta perfeitamente para o desenvolvimento regular ou normal da excreção urinária.

O vago e o simpático atuam alterando o ritmo do peristáltismo; o primeiro, excitando; o segundo, inhibindo.

Em diversas circunstâncias podem se instalar graves perturbações na dinâmica pielo-ureteral. Citaremos, primeiramente, a que decorre de interferências intempestivas, durante atos cirúrgicos, sôbre a parede do ureter. Os ferimentos desse órgão irão, certamente prejudicar a dinâmica ureteral, por lesar-lhe o substrato anatômico: células ganglionares e musculatura lisa. Se não bastasse tal inconveniente, lembrariamos a nocividade que adviria ao livre transito da urina, pela instalação de tecido cicatricial no seio da parede do órgão referido.

Em segundo lugar, trazemos o caso da acalásia.

(*) A dinâmica pielo-ureteral só pode ser identificada após a pieloureteroscopia de Legueu e da urografia excretora de Lichtenberg. Contestada por Marion é admitida por numerosos AA. Entre êsses, citaremos: Fey, Lagueu, Papin, Lichtenberg, Hinman, Mathe.
Heckenbach, e muitos outros. 
A acalásia (ausência de relaxamento de um esfíncter em presença da onda peristaltica) não é um fenomeno privativo do tubo digestivo, também atinge o aparelho urinario. (Eduardo Monteiro, São Paulo Médico n. ${ }^{\circ}$ ).

Discutem os A.A. quanto à existência de esfíncteres anatòmicos entre o bacinete e o ureter, e na parte terminal do ureter.

Entretanto, observando-se a ritmicidade do esvasiamento do bacinete, devemos concluir pela presença de esfíncter funcional pielo ureteral. A acalasia de tal aparelho esfíncteriano acarreta a formaçāo de megabacinete.

Satani, citado por Eduardo Monteiro, nega a existência do esfíncter ureteral inferior. A verificação de que o meato ureteral "se abre de tempos a tempos para dar passagem à urina" vem evidenciar a presença de um esfíncter funcional. A acalasia dêsse esfincter produz o megaureter.

A adinamia das vias excretoras do aparelho urinário, segundo Eisendrath e Rolnick pode sobrevir, às vezes, após o parto, devido à ação de toxinas que iriam perturbar o mecanismo neuro-muscular da excreção urinaria.

\section{FATOR ESSENCIAL NA ETIOLOGIA}

Qualquer que seja a causa considerada, quer mecânica ou dinâmica, quer congênita ou adquirida, estabelece-se nas vias excretoras a pressão retrógrada que é condição essencial para a instalação da hidronefrose.

A elevação da pressão retrógrada irá prejudicar o funcionamento renal, por alterar os elementos nobres do rim, atrofiando-os inicialmente, para destruí-los num periodo mais ulterior.

Afim de diminuir o valor de semelhante força concorrem diversos fatores. São êles:

A) absorção da urina de estase.

B) refluxos:

1) pielovenoso.

2) tubular.

3) intersticial (túbulo-venoso, túbulo-linfático).

Absorção da urina de estase: Está demonstrado que a urina de estase sofre absorção ao nivel da mucosa dos calices e do bacinete.

Refluxo pielo-venoso: A urina que está situada na pelvis pode por rutura do fornix papilo-calicial penetrar nas vênulas ou linfáticos.

Refluxo tubular: Com o aumento gradativo da pressão retrógrada em virtude do obstáculo e da secreção urinaria, há uma dilataçāo dos túbulos. O aumento do lumen dos túbulos "serve como válvula de escape" para a manutenção das duas pressões: pressão de secreção e pressão de excreção. 


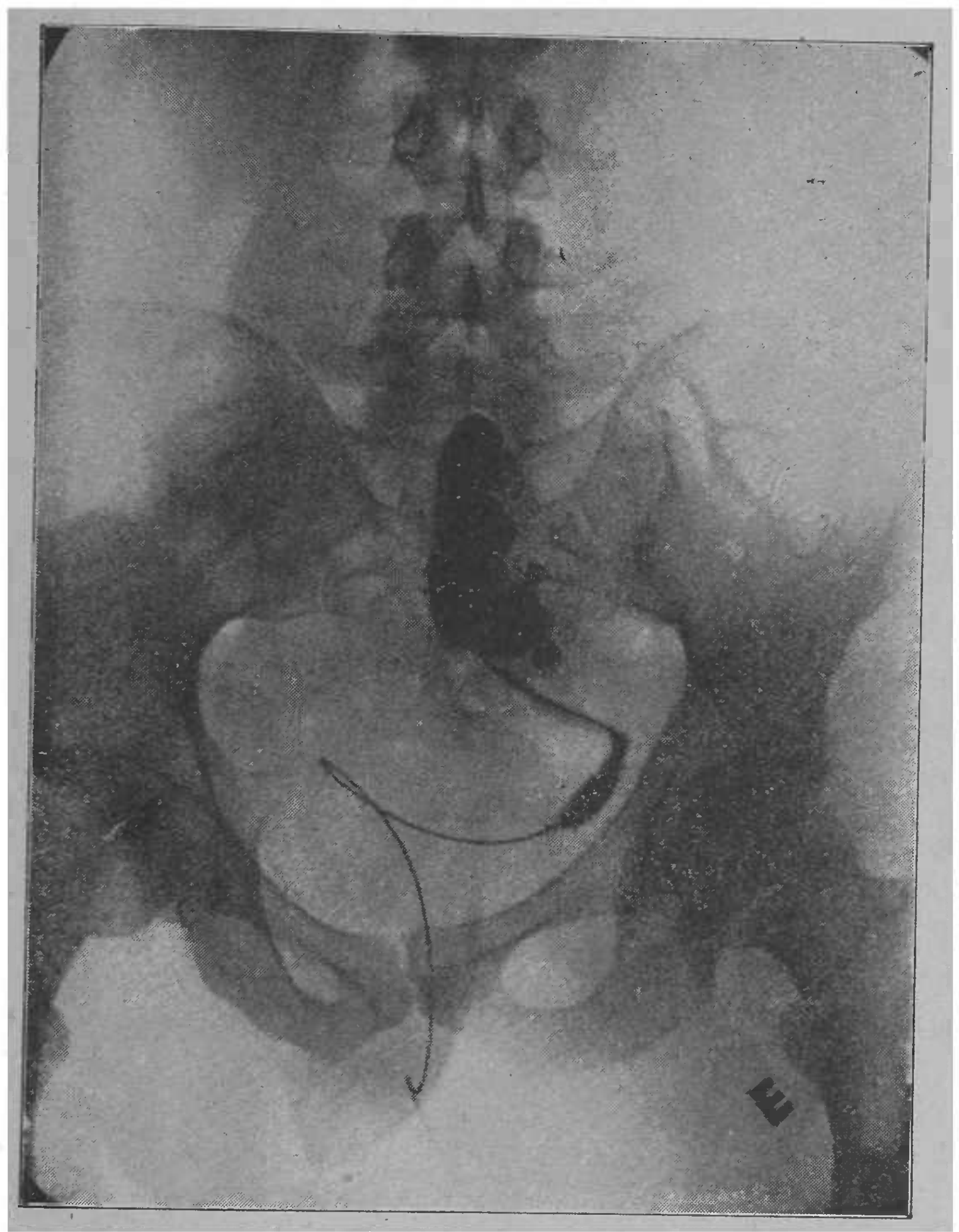

Rim pelvico - Hidronefrose com atrofia renal. Nefrectomia - Cura. 


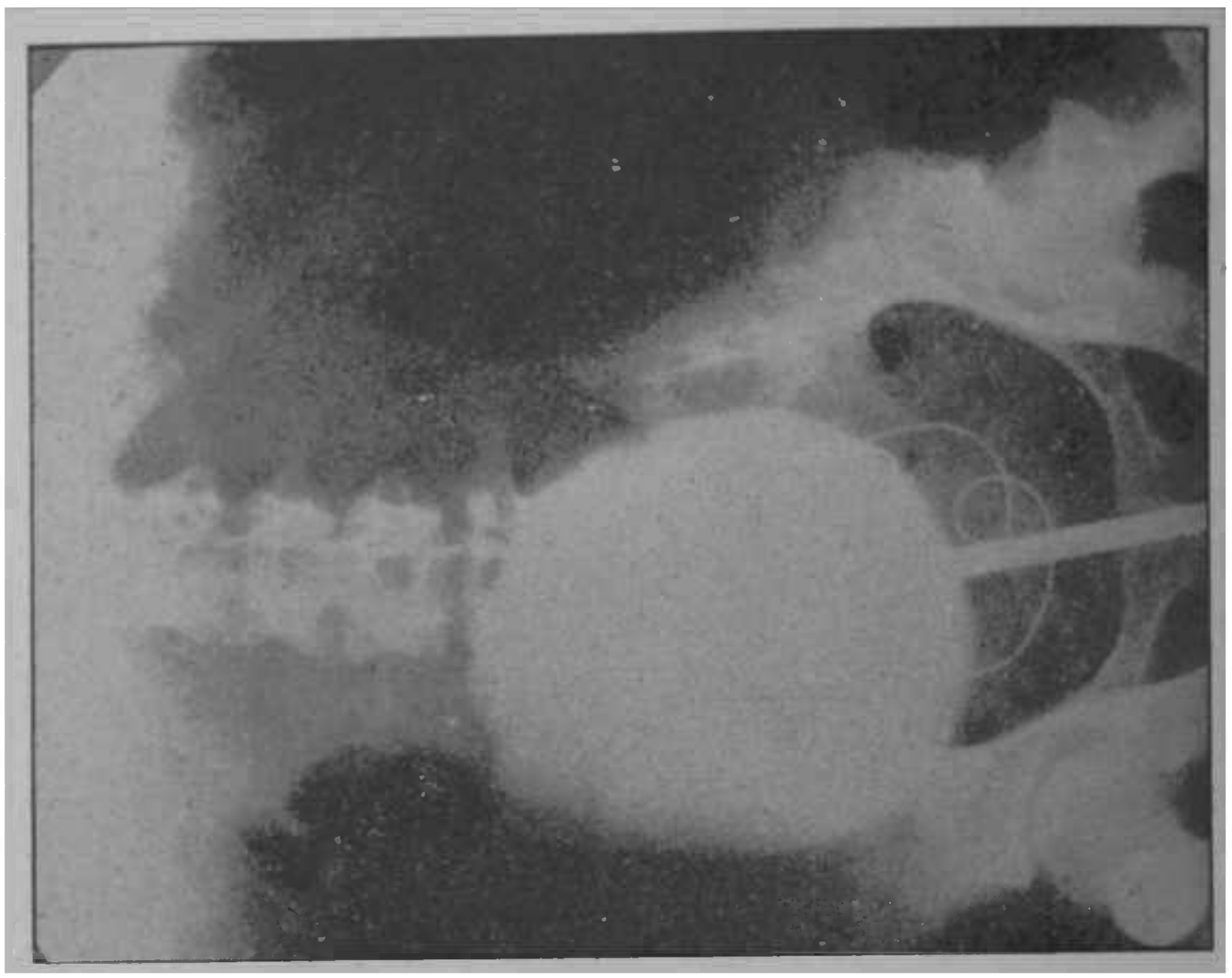

8

8

8

8

6)

8

in

密.

gु

워

용

尊

量

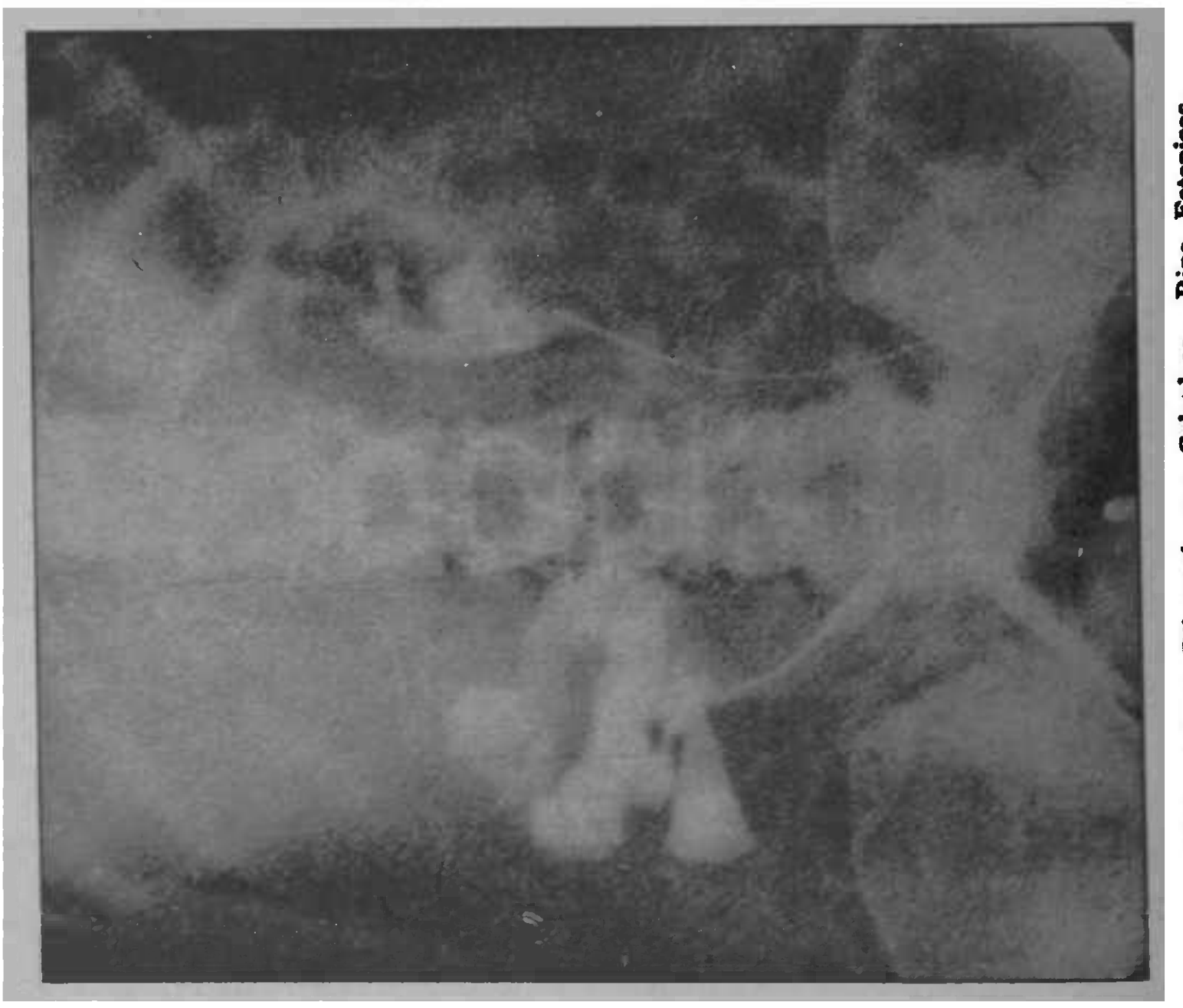

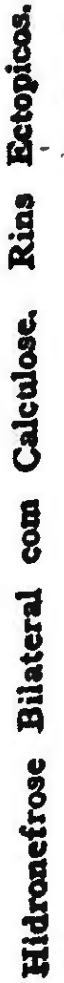




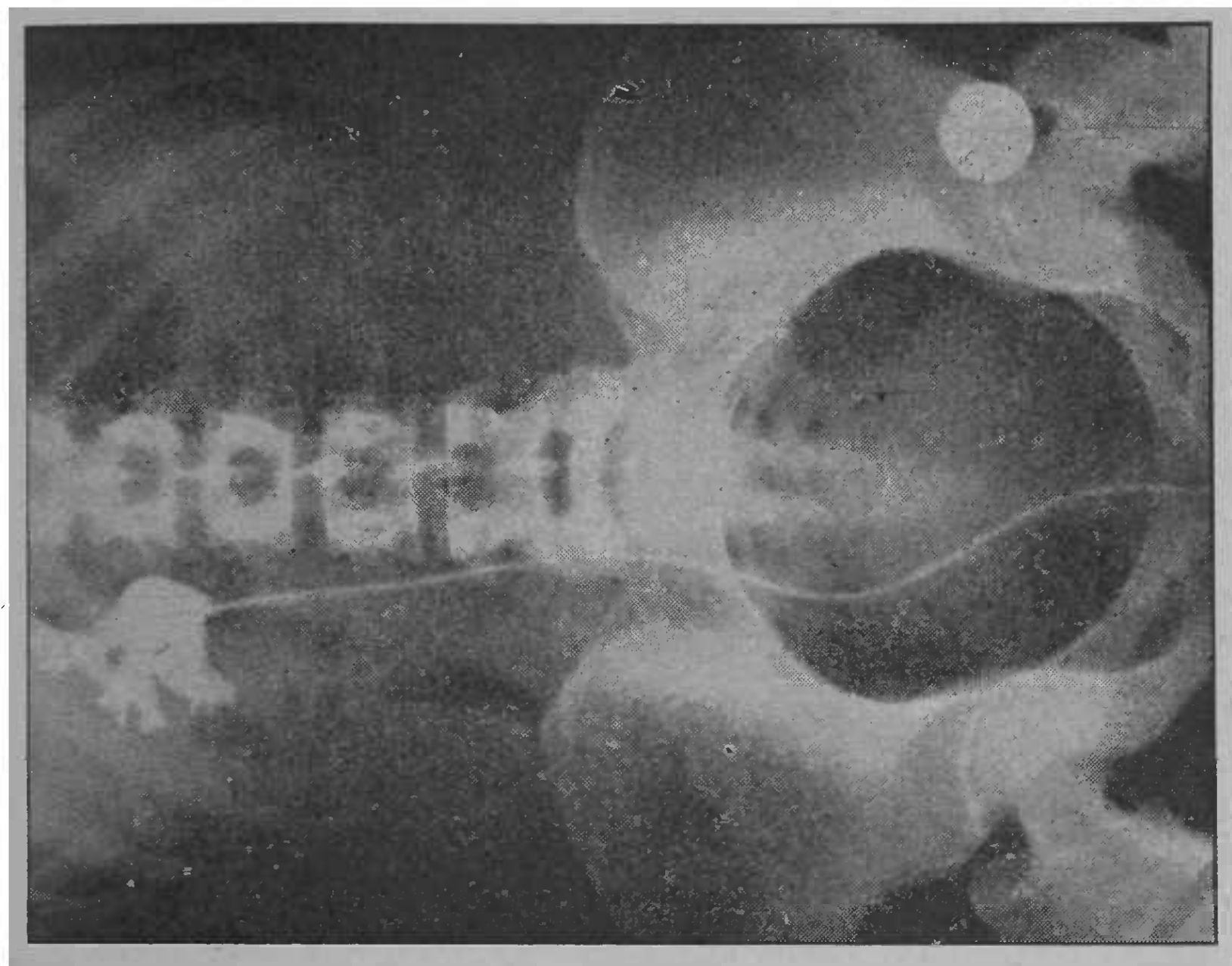

岌

总

A

离兽

递

密

莬

م.

म

苟

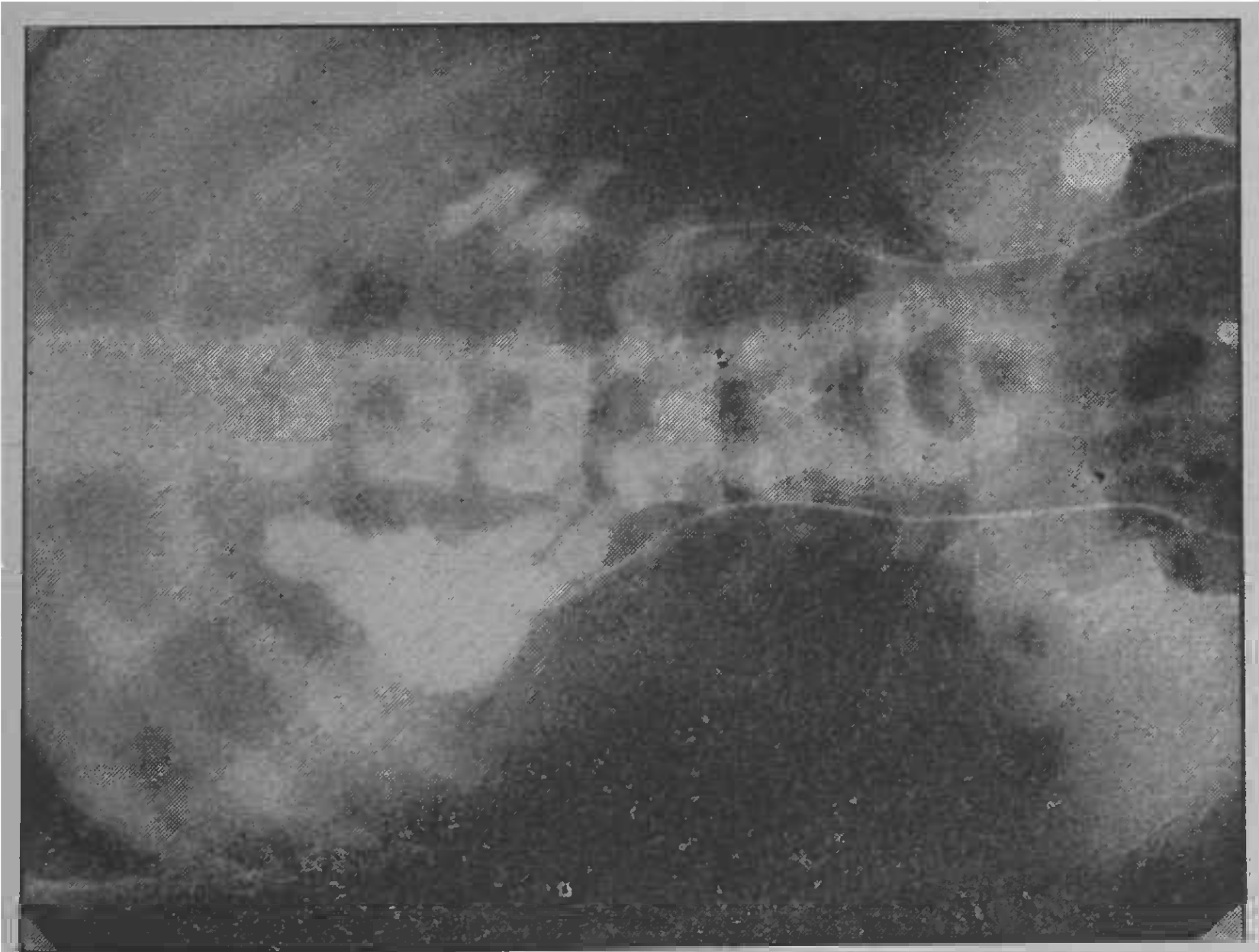

富

莡

究

웜

萬

岁

要

焉

焉

㝵

蛋 
Nota: O rim secreta quando a pressão de secreção se torna maior que a excreção. No momento em que a pressão de excreção sobrepuja a de secreção dá-se a contratura pielica, com consequente expulsão de urina para o ureter, esvasiando-se, por conseguinte, 0 bacinete.

Esquematicamente: P.S. $>$ P.E. = Elaboração de urina. P.E. > P..S. = Contratura pielica.

P.S. = pressão de secreção.

P.E. = pressão de excreção.

Refluxo intersticial: Processa-se êste refluxo quando a urina se extravasa para o interstício, devido a rutura das paredes dos canalículos. Esta urina pode pentrar numa venula ou linfático, daí a divisão dos refluxos intersticiais: túbulo-venoso e túbulo-linfático.

Em conclusão poderemos escrever: "Si a pressão retrógrada é o fator essencial para o desenvolvimento de uma hidronefrose, são os refluxos e a absorção os fatores controladores". (Enervação Renal - Tése 1.938. J. Martins Costa).

Tentam as vias excretoras com o fim de vencer o impecilho an livre escoamento da urina, a hipertrofia de suas fibras musculares e a hipercinesía.

Ora, se todo o músculo submetido a um trabalho exagerado se fatigar, não tardará o aparecimento de dilatação pela distensão que a urina provoca num órgão cuja musculatura, após a luta contra 0 obstáculo, acaba de perder a tonicidade e o poder contractil. E' a hidronefrose. (Conceito morfológico).

\section{BIBLIOGRAFIA}

LAWERS - Introduction à Chirurgie Genito-Urinaire. Hamburger, J. - Physiologie de l'innervation rénale. EISENDRATH e ROLNICK - Urology 1938.

MARIon - Traité d'Urologie.

Hinman - Principles and Practice of Urology 1936. HoEber, R. - Fisiologia Humana.

Costa Martins, J. - Enervação Renal. Tése, 1938.

Paulino, A. - Urologia.

Forgue - Compendio de Patologia Externa, volume II.

Revista Úrologica de São Paulo, Março-Abril 1937. ", Março-Abril 1935. 


\section{ORIENTAÇÕES PARA O USO}

Esta é uma cópia digital de um documento (ou parte dele) que pertence a um dos acervos que fazem parte da Biblioteca Digital de Obras Raras e Especiais da USP. Trata-se de uma referência a um documento original. Neste sentido, procuramos manter a integridade e a autenticidade da fonte, não realizando alterações no ambiente digital - com exceção de ajustes de cor, contraste e definição.

1. Você apenas deve utilizar esta obra para fins não comerciais. Os livros, textos e imagens que publicamos na Biblioteca Digital de Obras Raras e Especiais da USP são de domínio público, no entanto, é proibido o uso comercial das nossas imagens.

2. Atribuição. Quando utilizar este documento em outro contexto, você deve dar crédito ao autor (ou autores), à Biblioteca Digital de Obras Raras e Especiais da USP e ao acervo original, da forma como aparece na ficha catalográfica (metadados) do repositório digital. Pedimos que você não republique este conteúdo na rede mundial de computadores (internet) sem a nossa expressa autorização.

3. Direitos do autor. No Brasil, os direitos do autor são regulados pela Lei n. ${ }^{\circ}$ 9.610, de 19 de Fevereiro de 1998. Os direitos do autor estão também respaldados na Convenção de Berna, de 1971. Sabemos das dificuldades existentes para a verificação se uma obra realmente encontra-se em domínio público. Neste sentido, se você acreditar que algum documento publicado na Biblioteca Digital de Obras Raras e Especiais da USP esteja violando direitos autorais de tradução, versão, exibição, reprodução ou quaisquer outros, solicitamos que nos informe imediatamente (dtsibi@usp.br). 